\title{
Pintura mural en el siglo XVII sevillano
}

José Fernández López

Departamento de Historia del Arte Universidad de Sevilla

\begin{abstract}
Resumen
La pintura mural tuvo una presencia destacada en el siglo XVII sevillano, aunque, desgraciadamente y por distintas razones, se haya conservado relativamente poco, excepto de las últimas décadas de la centuria. La técnica predominante empleada fue la del temple con abundantes toques al óleo. Así lo señaló ya el tratadista y pintor Francisco Pacheco, quien en el Arte de la pintura..., publicado en 1649 , nos ofreció abundantes noticias sobre pintores sevillanos muralistas desde la segunda mitad del siglo XVI hasta el primer tercio del posterior. Los mejores intérpretes sevillanos de este tipo de pintura fueron Francisco de Herrera "el Viejo", Juan Valdés Leal y su hijo Lucas Valdés
\end{abstract}

\section{Palabras clave}

Pintura mural / Siglo XVII / Sevilla

Es opinión común en la bibliografía artística sobre la pintura sevillana del XVII insistir en que esta centuria fue su gran período, su auténtico Siglo de Oro. En verdad, no por repetido deja de ser menos cierto. Lo es sin duda porque desde sus inicios el primer siglo del Barroco trajo a Sevilla la combinación de elementos sociales y culturales necesarisos para que así ocurriera. Pero, indiscutiblemente, lo es también porque la fortuna o el destino quiso que en aquel momento nacieran o habitaran en esta tierra un conjunto de intérpretes excepcional calidad: Herrera "el Viejo", Zurbarán, Velázquez, Cano, Murillo, Valdés Leal...,etc. La pintura barroca sevillana, dentro del contexto de la escuela española del siglo XVII, alcanzará en este período personalidad propia y diferenciada en estilos y creatividad en los modelos; bien es cierto que estos últimos casi totalmente vinculados con los planteamientos icónicos derivados de la Contrarreforma y de la cultura dirigista de la época.

Aunque todos estos elogios iniciales sean merecidos y ciertos, y muchos más que podrían añadirse en un listado que por profuso pudiera ser enojoso, se constatan también en la mayoría de los análisis algunas lagunas y cuestiones todavía sin respuestas sistematizadas. Así, por ejemplo, ¿este encomiástico preámbulo afecta por igual a todas las temáticas desarrolladas en la escuela sevillana del seiscientos?, y, especialmente, ¿afecta por igual a todas las técni- cas y a todos los soportes pictóricos utilizados?. En este último caso, la mal llamada pintura decorativa sobre soporte mural o parietal no alcanzó en Sevilla durante el siglo XVII los niveles de entidad artística protagonizados por la pintura realizada sobre lienzo con la técnica del óleo. De hecho tardíamente, sólo a partir de las últimas décadas de esta centuria, este tipo de pintura parece alcanzar, al menos en lo conservado, un desarrollo de entidad, gracias a la producción de artistas como Juan Valdés Leal y su hijo Lucas Valdés. Esta producción se mantendrá en el siglo XVIII siempre dentro de niveles apreciables que no sobresalientes.

En realidad a este campo de la pintura en la escuela sevillana sólo se le han venido dedicando comentarios muy generales, si se llegaban a hacer, en obras globales. Aparecen también referencias en aquellos trabajos sujetos a planteamientos biográficos, siempre muy importantes, pero carentes de la necesaria visión de conjunto. Algo parecido ha ocurrido con algunas monografías dedicadas al estudio de edificios que contienen conjuntos pictóricos de este tipo. La vía iconográfica ha abierto algunas puertas para el concimiento de programas en los que se ha intentado, sobre todo, marcar líneas de estudio iconológicas. Tenemos noticias también de algunos trabajos de investigación nacidos en el seno universitario que, aún, permanecen inéditos. Loable ha sido el esfuerzo de algunos, como en tiempos Celestino López Martínez y más recientemente Juan Miguel González Gómez, por sistematizar y hacer un recorrido evolutivo en épocas concretas o durante la Edad Moderna !. Nos encontramos pues ante un campo abierto a la investigación histórico artística y técnica, en el que las dificultades han de ser el mejor acicate para mejorar y ampliar su conocimiento y vigilar en lo posible por su salvaguarda.

Como en todo el ámbito español, a excepción de la Corte o de algunos conjuntos aislados de identidad temática mitológica, histórica o puramente decorativa, la pintura religiosa ocupa, destacada, el primer lugar entre los asuntos abordados en la pintura mural. Desde la óptica de la Contrarreforma, los valores culturales del Barroco fueron adaptados a la esfera de la Religión como cauce de expresión de un nuevo simbolismo social. Tras la publicación de los decretos del Concilio de Trento, sobre el mundo católico se cierne una ola de intransigencia religiosa y moral, curiosamente planteada como una Reforma Católica, propiciada por la autoridad y la tradición de la Iglesia. Como indicó Blunt: "El efecto de la Contrarreforma sobre las artes fue similar al que tuvo en las demás ramas de la cultura y el pensamiento" 2 . Este efecto tenía esencialmente un carácter psicológico, ligado al autoconvencimiento en la bondad de los valores dominantes que, para perpetuarse, adoptan un carácter sacralizado o divinizado. Las premisas marcadas fueron:"nihil profanun, nihil insoli- 
tum nihique inhonestum"; alejando todo aquello carente del "decoro" necesario. El predominio de la "Verdad" sobre la Belleza, definen al pintor cristiano ante la sociedad convirtiéndolo en una especie de orador sagrado que ha de convencer mediante su obra de la verdad de los valores piadosos y morales y de los beneficios y recompensas de los mismos sobre el hombre. Señaló el tratadista jesuita Gabriele Paleotti, que el pintor no sólo tiene la capacidad de persuasión a través de las imágenes sino que ese poder que está en sus manos ha de ser utilizado en la defensa de las creencias y las virtudes ${ }^{3}$. La nueva mentalidad manifestaba el predominio de los valores teológicos a un doble nivel o estructura de poder: de una parte político, en el control del Estado por el absolutismo, y de otra religioso, dominador de las conciencias. Monarquía e Iglesia, Estado absolutista y Religión configurarán el "status" imperante en el control de la sociedad del Antiguo Régimen, tanto en los estados católicos como en los protestantes. Sin embargo, ese control social y cultural ejercido por el poder en el siglo XVII tuvo diversas formas y manifestaciones aplicables a las distintas actividades de la época, dentro de una concepción unitaria de la vida.

En España, como indicó Maravall, "decir Barroco español equivale tanto como a decir Barroco europeo visto desde España" 4 . Por ello este país, y Sevilla, la "Menfis de Castilla" como la llamó Tirso de Molina ${ }^{5}$, participó del carácter general de la cultura barroca, pero adaptándola de una forma tan personal que ha llevado a pensar a algunos investigadores, en diversos aspectos, en su origen hispano ${ }^{6}$. Fue en la nueva iconografía postridentina donde quedó más patente, en el mundo artístico, la influencia del dirigismo ideológico. En las artes plásticas, la religión tomó cuerpo con sus ritos y sus prácticas, transformando en objeto artístico el ceremonial eclesiástico. Todo ello dio origen a una iconografía de carácter mímico, convencional y comprensible para los creyentes, en opinión de Weisbach ${ }^{7}$. Por otro lado el concepto hierático de la representación religiosa se altera en este momento por un sentido narrativo, mucho más comprensible a nivel popular. Se estructuran a partir de entonces en las denominadas "historias", bíblicas, eclesiásticas, monásticas o hagiográficas. El fundamento de la "historia" radica en el intento de alejar los valores abstractos de los conceptos teológicos, acercándolos al hombre a través de lo emocional. También las exaltaciones apoteósicas hagiográficas y los temas teológicos más complejos participaron de esta nueva mentalidad.

La pintura configurada de manera programática parece pues el mejor vehículo de expresión de estos ideales, pudiéndose estructurar, en el marco de una señalada retórica visual, en series de lienzos, en retablos (marcos arquitectónicos para contener pinturas en sus registros), o en pinturas murales. Todas estas manifestaciones artísticas estuvieron presentes en diversos espacios dentro de los edificios religiosos. Sólo a la pintura mural se le reservan además bóvedas y cúpulas.

\section{La primera mitad de siglo}

Tenemos noticias sobre la actividad decorativa mural de pintores sevillanos o vinculados a la escuela desde comienzos del siglo XVII. Nuestra fuente de conocimiento de especial interés en este momento es, como tantas veces en la pintura sevillana, el tratado de Francisco Pacheco, Arte de la pintura..., publicado en Sevilla, en 16498. El famoso suegro de Velázquez, en el capítulo III del Libro III de su obra, escribe sobre la técnica del fresco, dejándonos jugosas noticias sobre pintores sevillanos expertos en esta técnica desde la segunda mitad del siglo XVI, de los que sobre todo destaca a Luis de Vargas, pintor al que admira y refiere como el primero que trajo a Sevilla esta técnica del fresco en 1555 con su Virgen del Rosario, del convento de San Pablo, perdida ya en época de Pacheco. Cita además otras obras murales de Vargas como el Arco del Sagrario, la decoración de la Giralda y de las Gradas de la Catedral de Sevilla. Pacheco, durante su extensa vida artística, iniciada en Sevilla a partir aproximadamente de 1585, conoció a los mejores muralistas activos en la ciudad desde la etapa manierista hasta la fase final de introducción y consolidación naturalista del primer barroco, hacia I625. Entre los citados por el tratadista debe destacarse a Pablo de Céspedes, amigo y consejero artístico e iconográfico personal, como evidencia la "Doctíssima carta de la pintura" que remitió a Pacheco en I608, año de su fallecimiento. Céspedes fue pintor de estirpe manierista, nacido en Córdoba, hacia I548, y formado en Roma desde I 570 aproximadamente. Hombre culto y el primer gran teórico español del arte pictórico, entabló amistad en la Ciudad Eterna con Federico Zuccaro, realizando obras al fresco como en la iglesia de la Santa Trinitá dei Monte. De vuelta a su Córdoba natal, en I577, su labor allí dejará honda huella en los pintores de aquella escuela. Su presencia en Sevilla, intermitente desde 1585 hasta 1603 , dejó también impronta en la escuela sevillana de finales del siglo $\mathrm{XVI}$ y comienzos del $\mathrm{XVII}$, en especial en la técnica del fresco, que ejerció con un estilo vigoroso propio del manierismo romano. También se cita en este apartado por Pacheco la labor de Mateo Pérez de Alesio, activo en Sevilla entre I 584 y I 585.

La presencia de estos artistas en la entonces metrópolis andaluza, fue esencial en la formación de los artistas de la generación posterior. A muchos de estos jóvenes pintores les unía su vinculación y hasta admiración por la pintura mural ejecutada al fresco. Francisco Pacheco lo expresaba así:

"Viniendo pues a su execución: de todos los modos que los pintores usan, el pintar en pared a fresco es el más magistral, de mayor destraza y expedición. Consiste en pintar en un día y de una vez lo quede las otras maneras dura mucho y se puede retocar. Quiere gran destraza y resolución; sus yerros no son remediables si no se vuelve a desencalar y derribar lo hecho. Es una pintura más varonil y más eterna y, así, a los que la exercitan bien se les debe mayor reverencia y estima, como a mayores maestros" 9 . 
Aun así el tratadista comprende las dificultades que trae aparejado este uso pictórico por lo que señala:

"En cuanto a retocar a temple después de seca la pared, hay muchos de parecer contrario, no obstante que lo usaron valientes hombres como Mateo Pérez de Alecio en el S. Cristobal y la puerta del Cardenal, Antonio Mohedano y Alonso Vázquez en el claustro de S. Francisco,..." 10.

El rondeño Alonso Vázquez (h. I563-h. I 608), activo en Sevilla desde 1588 hasta su marcha, en 1603, hacia a México, fue pintor formado en el manierismo que evolucionó en su última etapa profesional apareciendo en sus obras algunas dosis de naturalismo, especialmente bodegonista pero también resaltando la expresión y el colorido, aun sin renunciar a los modelos anteriores pues era buen conocedor de los esquemas flamencos de Martín de Vos y de Cornelis Cort entre otros. El lucentino Antonio Mohedano (h.1563-1626), permaneció en Sevilla algo más de tiempo, hasta 1610 . Fue pintor de formación manierista, autor de composiciones de rígida simetría, dibujo severo que marca los perfiles de las figuras y resalta los amplios pliegues de los ropajes, cierta frialdad en la expresión y coloridos vivos e ideales. Ese cromatismo, alejado de la realidad, contrasta con la dedicación de Mohedano al bodegón, especialmente comentada por el tratadista $\mathrm{Pa}$ checo, quien alaba sus cualidades en este campo y también para la pintura mural"'. Quizás, como Blas de Ledesma, pintor del ámbito granadino, Mohedano debió formarse en este campo en los círculos cercanos a los pintores de grutescos Julio de Aquilis y Alejandro Mayner. Se advierte en su obra un exquisito sentido decorativo en la descripción de las formas naturales: pajáros, flores y frutas. Talvez por ello Ceán Bermúdez le atribuyó de antiguo los elementos ornamentales de las orlas de los techos del Salón Principal y la Galería del Prelado del Palacio Arzobispal de Sevilla 12. Como señaló Pacheco, Mohedano y Alonso Vázquez pintaron al fresco retocado al temple las paredes del claustro grande del convento de San Francisco de Sevilla. De ese conjunto, hoy desgraciadamente perdido y que fue posiblemente ya retocado a inicios del siglo XVIII por Lucas Valdés, Francisco Pacheco destacó los festones de frutas hechos por Mohedano ${ }^{13}$. Se conserva actualmente de este artista las pinturas de la bóveda del presbiterio de San Mateo de Lucena, datables hacia 160014

La técnica del temple, con distintas variantes, y con retoques al óleo, parece imponerse en la pintura mural sevillana a lo largo del siglo XVII. Esto no quiere decir que no se cultivara el fresco, pues se conservan algunos ejemplos, que sin ser relevantes por su calidad artística sí presentan una razonable entidad. El monasterio de San Isidoro del Campo, en Santiponce, ofrece diversas muestras anónimas. Su sala capitular está decorada con pinturas de la primera mitad del siglo XVII, que reproducen en la cubierta las Virtudes mientras en los muros laterales se pintaron las figuras de San Jerónimo y San Isidoro y diversos pasajes de la vida de Cristo. En la capilla Privada o del Reservado se conservan algunos frescos de comienzos del seiscientos, en los que sobresalen algunos emblemas marianos en orlas de estilo manierista. Finalmente en el claustro de los Muertos de este cenobio se pueden contemplar frescos que representan diversos miembros de la orden jerónima ${ }^{15}$.

Hacia los inicios del segundo cuarto del siglo XVII, el mejor pintor muralista sevillano fue Francisco de Herrera "el Viejo". En la decoración de los interiores eclesiásticos en esta época predominan los motivos de yeserías, habitualmente policromadas, que podían llevar unido a este lenguaje ornamental la presencia de una decoración mural pictórica figurativa. En los citados motivos ornamentales perviven los diseños y modelos derivados del estilo manierista, y, resaltándose en los huecos dejados por marcos y tarjas, pinturas en las que se reflejan escudos, emblemas y empresas, retratos y otros motivos religiosos. Estos conjuntos pueden completarse con la presencia de lienzos en serie de carácter devocional o desarrollando las ya citadas "historias" de la Redención o hagiográficas. Hay que recordar también que muchas pinturas murales de esta época y anteriores se perdieron tras los encalamientos profilácticos de muros y bóvedas en muchas iglesias después de la peste que asoló la ciudad a mediados del siglo XVII.

Francisco de Herrera "el Viejo" (I 590-1654), fue uno de los pintores más interesantes de la primera mitad del siglo XVII sevillano como demuestra, con altibajos, su producción artística. Su estilo evolucionó desde las fórmulas manieristas hacia el naturalismo con formas muy vigorosas, severas a veces en la expresividad, con una pincelada suelta y un cromatismo que recuerda en muchas ocasiones la técnica veneciana. Entre sus obras más destacadas debemos recordar La apoteosis de San Hermenegildo (Sevilla, Museo de BB. AA.), de 1620, la serie de San Buenaventura, comenzada hacia 1627 y rematada por Zurbarán, o el Juicio Final(Sevilla, parroquia de San Bernardo), de 1628. En su etapa final el expresionismo de los personajes se dulcifica, aunque mantenga la monumentalidad corporal, y su técnica se hace aún más suelta. Sirva de ejemplo las tres versiones de su San José con el Niño que se conocen, realizadas a partir de 1645, de las que destacamos la conservada en el Museo Lázaro Galdiano, Madrid. Fue Herrera "el Viejo" un buen grabador, producción no habitual entre los pintores sevillanos de su época ${ }^{16}$.

El Colegio franciscano de San Buenaventura, situado en el ámbito del desparecido convento Casa Grande de San Francisco de Sevilla y cuyos orígenes da$\tan$ de 1600, fue instituido como centro de altos estudios teológicos de la orden, constituyendo la única institución de estas características de los franciscanos en España, durante la primera mitad del siglo XVII. En el año 1626, los alarifes Juan Bernardo de Velasco y Juan de Segarra conciertan la realización de la decoración estucada de la iglesia del colegio, diseñada por Francisco de Herrera "el Viejo", quien, 
entre 1626 y 1627, acometía las pinturas murales de las bóvedas: retratos, empresas morales y escudos. El rico repertorio ornamental y figurativo que decora las bóvedas de este templo, presenta un programa intelectual y religioso de gran profundidad, entroncado en los principios filosóficos de San Buenaventura y en los caractéres generales de la espiritualidad seráfica. Martínez Ripoll estudió con profundidad este programa iconográfico, desentrañando el lenguaje simbólico que de su decoración emana, vinculándolo con los textos bonaventurianos e indicando las direcciones iconológicas de su contenido dentro de la actividad y función del Colegio. Recientemente Chavero Blanco ha propuesto una nueva lectura iconológica de la decoración de este templo concluyendo que su contenido exalta, a partir del lenguaje del barroco, la ciencia y la santidad desde el sentido y la obra bonaventurianos 17.

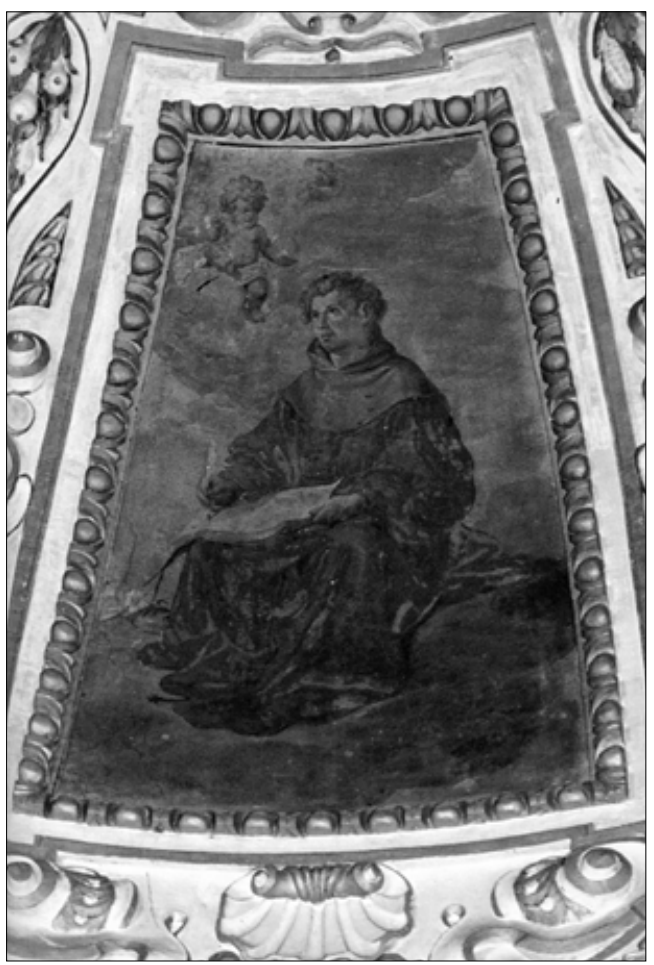

Foto |: Francisco de Herrera "E Viejo". San Antonio de Padua. Iglesia de San Buenaventura. Cúpula.
Pero el programa pictórico de la iglesia del Colegio de San Buenaventura no termina aquí, fue completado con un ciclo de lienzos, conmemorativos de la vida y las virtudes religiosas del santo patrón del templo, San Buenaventura. Este ciclo, que fue realizado desde 1627 a 1629, estaba compuesto por ocho lienzos de Herrera "el Viejo" y Francisco Zurbarán y colgaron de las paredes de la nave central de la iglesia colegial hasta su dispersión en 1835. La serie estaba dividida en dos, física y temáticamente. Herrera reprodujo en sus lienzos del lado derecho hechos de la infancia y primera vocación de San Buenaventura: Aparición de Santa Catalina de Alejandría a los familiares del Santo, San Francisco curando a San Buenaventura niño, San Buenaventura tomando el hábito de la orden franciscana y San Buenaventura recibiendo la comunión de un ángel. Zurbarán pintó, en el lado de la Epístola, los relativos a la madurez y la muerte del Doctor Seráfico: San Buenaventura recibiendo la visita de Santo Tomás de Aquino, San Buenaventura confortado por el ángel, San Buenaventura en el Concilio de Lyón y Muerte de San Buenaventura. La explicación a esta tajante separación ha sido desarrollada por Odile Delenda, partiendo del texto reformado del Breviario Romano, en 1568, durante el período del pontificado del Papa San Pio V, quien había nombrado a San Buenaventura doctor de la Iglesia con los mismos honores que Santo Tomás de Aquino ${ }^{18}$.

\section{La segunda mitad del siglo}

El desarrollo de la decoración pictórica mural del pleno barroco llega a España con posterioridad a mediados del siglo XVII, a través, como todas las novedades desde aquel momento, de la Corte. Herederos de la tradición pictórica mural clasicista romano boloñesa, aunque colaboradores del famoso Pietro da Cortona, fueron los pintores Agostino Mitelli y Angelo Michele Colonna, cuya venida a España, en 1658, fue gestionada por Velázquez durante su segunda estancia en Italia. Su actividad fue esencial para el desarrollo de la pintura mural española, tanto por su trabajo en la decoración de viejo Alcázar madrileño y en los salones del palacio del Buen Retiro, como por la enseñanza a los pintores españoles que colaboraron en sus trabajos, Juan Carreño Miranda y Francisco Rizi. Ambos pintores italianos, con la técnica del fresco, trajeron a España la fórmula de la quadrattura, con dominio de la perspectiva en la figuras y en las arquitecturas fingidas, aunténticos trompe-l'oeil, capaces de enmarcar escenas diferentes: mitológicas, históricas o religiosas. Aparte de la técnica, este tipo de pintura requería del artista un gran dominio de la geometría proyectiva que permitía disponer los elementos arquitectónicos sobre superficies curvas (bóvedas, cúpulas y pechinas), sin distorsionar los puntos de fuga compositivos. En buena parte, partiendo del trabajo de estos pintores, se desarrolló en la corte un estilo decorativo parietal de dibujo movido y ágil, de concepción vibrante en el color y de gran corrección en la concepción de las escenografías. Todos esas 
novedades alcanzadas y asumidas en estos momentos no habían sido propias en la pintura española hasta la fecha y su difusión por todas las escuelas provinciales tuvo una considerable repercusión.

A mediados del siglo XVII, se produce en Sevilla el triunfo y la consolidación definitiva de las formas del pleno barroco. Introducido lentamente desde algunos años antes el dinamismo rubeniano, el comedio del siglo trae consigo un viraje en la actividad de muchos pintores locales hacia un arte de mayor vehemencia expresiva, vitalidad física y aparato escenográfico en fondos, vestimentas, coloridos y luces. Este estilo del llamado barroco dinámico y teatral, que no parece atraer mucho a Velázquez en la Corte, fue introducido en Sevilla, o al menos su presencia aquí jugó un papel esencial, por Francisco de Herrera "el Mozo" (1627-I68I). Este pintor nacido en Sevilla, realizó su formación con su padre, el ya citado Herrera "el Viejo", a quien abandonó tras sugir entre ambos diferencias irreconciliables que conocemos a través de leyendas. Parece que completó su formación en Italia, aunque aún no tenemos constancia documental de ese viaje. De ser esto cierto, imbuido ya en el barroco triunfal y dinámico aprendido en aquellas tierras, debió regresar a España en 1650 y a su ciudad natal en 1655, dejando aquí algunas piezas esenciales de su carrera artística, como El triunfo de la Eucaristía (Sevilla, Hermandad Sacramental del Sagrario), y el Éxtasis de San Francisco (Sevilla, Catedral) ${ }^{19}$. Su estancia en esta ciudad debió ser un serio acicate para los pintores locales, quienes pudieron conocer, gracias a las aportaciones de un pintor de gran categoría, las novedades de vanguardia en el ambiente artístico español. Su prestigio sin duda fue grande, por ello en el momento de la formación de la Academia de Pintura sevillana, en 1660, se le nombró presidente junto con Murillo. No ocupó mucho tiempo el cargo, pues ese mismo año partió para Madrid, donde desarrolló lo más importante de su carrera artística hasta su fallecimiento.

A pesar de la importante presencia en Sevilla de Herrera "el Mozo", la gran figura de la pintura sevillana de mediados del siglo XVII fue Bartolomé Esteban Murillo. Sin embargo, Murillo no fue pintor muralista. De hecho esta técnica parece estar en decadencia en Sevilla hasta la década de los setenta del siglo. No dejan de ser hipotéticas las posibles enseñanzas que Herrera "el Mozo" pudiera dejar en Sevilla respecto a la pintura mural, más aún teniendo en cuenta su posible conocimiento directo de los grandes pintores decoradores del pleno barroco romano. Efectivamente, desde la década de los treinta del siglo XVII, la cabeza visible de esta generación de pintores, Pietro da Cortona, creó un estilo de pintura mural llamado entonces "heroico", otorgando a sus escenas un sentido aparatoso y teatral. Con este estilo realizó diversas obras decorativas, entre las que destacan las bóvedas del palacio Barberini, en Roma, varios salones del palacio Pitti, en Florencia, y, nuevamente en Roma, trabajó en el palacio Pamphili y en el oratorio de los Filipenses.
Fue Juan Valdés Leal (1622-1690), el último de los grandes maestros de la pintura barroca sevillana del siglo XVII. Su personalidad artística y su arte fueron enérgicos y expresivos, llenos de vitalidad física y anímica en los modelos, y de técnica muy suelta y restregada. Resulta conveniente huir de los tópicos al referirnos a este pintor, tradicionalmente vinculado con temas macabros. Su actividad fue amplia y variada en el campo artístico. Su obra pictórica fue desigual, pero siempre dotada de personalidad singular. Lo mejor de su trabajo se concentra a partir de 1660. Sin embargo, con anterioridad realiza obras importantes como la serie del convento de Santa Clara de Carmona, el retablo mayor de la iglesia de las Carmelitas de Córdoba, la serie de la sacristía de San Jerónimo, en Sevilla, y el retablo de San Benito de Calatrava de la misma ciudad. En estos conjuntos se puede observar el carácter artístico de Valdés Leal, firme en el dibujo y algo desmañado en el color, y su evolución hacia las formas del pleno barroco. Aunque lógica pudo ser la influencia sobre su estilo del pintor Antonio del Castillo durante sus estancias en Córdoba, parece que la proyección de la escuela sevillana hacia 1656; el contacto con artistas madrileños como Francisco Rizi y Claudio Coello y, posiblemente, el conocimiento de obras foráneas flamencas e italianas, configuraron definitivamente su forma de pintar en la madurez. La impronta de sus figuras junto con la tendencia escatológica de los temas de muchas de sus obras, han sigularizado y dado a este artista una personalidad indiscutible, adecuada a los cánones estéticos del barroco español, a los mensajes de su cultura religiosa. Prueba de ello es que Valdés Leal, en sus más conocidas pinturas Los jeroglificos de las Postrimerías (Sevilla, Hospital de Santa Caridad), tradujo con genialidad el mensaje ascético popular de Miguel de Mañara en su Discurso de la verdad, publicado en Sevilla en 167| 20.

Los contactos de Juan Valdés Leal con el mundo de la Corte pudieron vincularle con la pintura decorativa mural en un lenguaje ya asimilado del pleno barroco. Es posible que el primer trabajo mural de interés acometido por el maestro fueran las pinturas eucarísticas de la capilla sacramental de la parroquia de San Andrés de Sevilla. Esta obra, recientemente recuperada, pudo realizarla Valdés Leal hacia 1670 1675, puesto que en esas fechas aproximadamente pintó los quince medallones que decoran el retablo de la Virgen del Rosario de dicha capilla. Años más tarde Valdés Leal acometió la decoración de la iglesia del Hospital de la Santa Caridad donde, entre 1680 y 1682 , pintó al temple los cuatro evangelistas de las pechinas, los cuatro santos de los arcos laterales del crucero (San Martín, San Julián, Santo Tomás de Villanueva y San Juan Limosnero), y los ángeles pasionistas de la cúpula ${ }^{21}$. Casi contemporánea fue la decoración mural que Valdés Leal realizó desde 1680 y hasta 1683, en el Real Monasterio de San Clemente. Más tarde, a partir de 1689, Lucas Valdés acometió la finalización del conjunto, debiéndose a este artista la impronta final del mismo. Realizada la obra como las anteriores al temple con retoques al óleo, además de los motivos puramente ornamenta- 


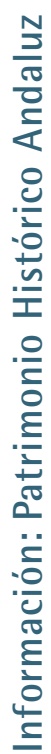

Foto 2: Juan Luis Valdés Leal. Veneración del Cuerpo de Cristo. Iglesia de los Venerables. Bóveda del prebisterio. les, remodelados en buena parte a mediados del siglo XVIII, los muros recogen diversos episodios figurativos. En el presbiterio: La lactación de San Bernardo, San Clemente haciendo brotar el agua del desierto, San Benito con Santa Escolástica y La recuperación milagrosa del cuerpo de San Clemente del mar. En las pechinas de la cúpula: San Juan, San Marcos, San Mateo y San Lucas. Finalmente sobre el muro del coro se colocó un lienzo, que forma parte del discurso decorativo del templo representando: San Fernando entrando en Sevilla22.

El mejor conjunto mural iniciado por Valdés Leal fue el de la iglesia del Hospital de los Venerables, uno de los más interesantes del barroco sevillano. El trabajo comenzó, según la documentación conservada, en 1686. La edad del maestro y su estado de salud maltrecho motivaron la intervención de su hijo y discípulo Lucas Valdés. La decoración fue iniciada por las bóvedas de la cabecera, y desde ellas hasta las de los pies, las pinturas de esta iglesia presentan un mensaje eclesiológico de exaltación de la condición y el ejercicio sacerdotal cristiano a través de los tiempos. Este objetivo se logró remontándose mediante textos al Antiguo Testamento, ejemplificándo-

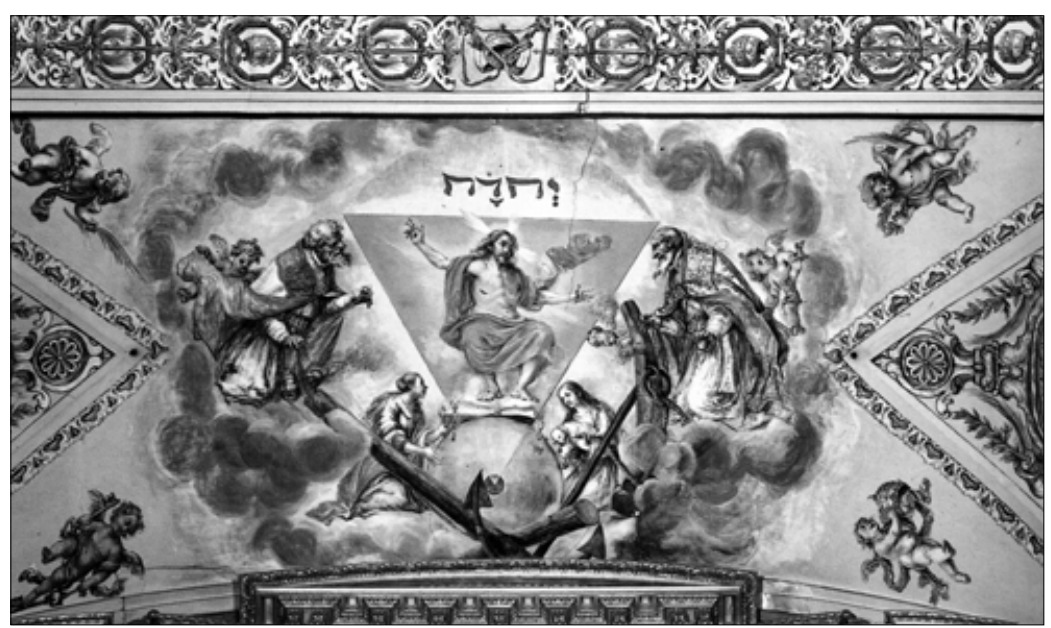

Foto 3: Lucas Valdés con diseño de Valdés Leal. San Martín presidiendo la mesa del emperador. Iglesia de los Venerables.

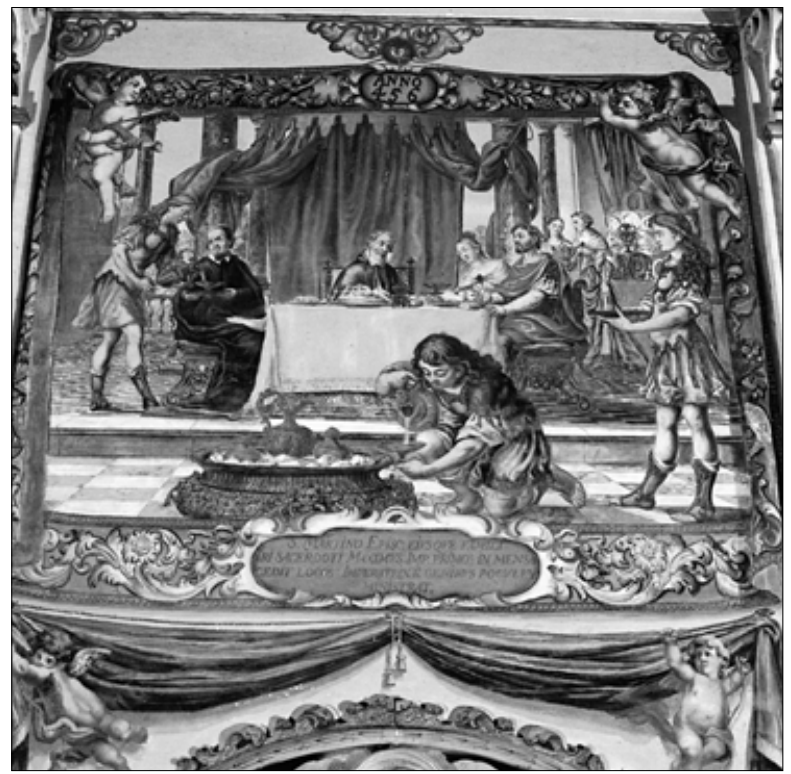

lo con sucesos históricos representados en las paredes de la nave y resaltando el papel renovado que Jesucristo concede al sacerdocio a través de su Sacrificio. El contenido ideológico de estas pinturas está en consonancia con el carácter histórico de la institución del Hospital de los Venerables Sacerdotes y con las directrices de la Iglesia tendentes a dignificar la labor del clero y su presencia ante la sociedad.

En las bóvedas y muros de esta iglesia podemos encontrar asuntos como la Veneración del Cuerpo de Cristo, por San Pedro y San Clemente, acompañados por las alegorías de la Caridad y la Humildad (Foto 2). Desde este primer tramo del prebiterio, las pinturas murales muestran un diestro sentido de la perspectiva y un cromatismo marcado y armonioso. El antepresbiterio, que se cubre con cúpula sobre pechinas, está totalmente decorado con motivos ornamentales y figurativos. En las pechinas y muros laterales de este espacio se aprecian los valdesianos modelos de ángeles mancebos acompañados de otros niños que portan utensilios de la misa y vestimentas eclesiásticas. En medio de esta exuberancia decorativa queda espacio en los muros para las representaciones inferiores del Ángel de la guarda a la izquierda y de Tobías y el ángel a la derecha. La media naranja presenta ocho medallones que simulan bronce dorado con la imagen de santos arzobispos y obispos de la primitiva iglesia española: San Laureano, San Flaviano, San Carpóforo, San Julián, San Fulgencio, San Cecilio, San Ildefonso y San Pío.

Sobresale en todo el aparato ornamental de las bóvedas de la nave de la iglesia de los Venerables la presencia angélica que, en su función mediadora ante los hombres, es equiparada a la de los sacerdotes. El lenguaje de los símbolos, bien sea de las virtudes y dones eclesiásticos, del papado y de los santos patronos del Hospital, San Pedro y San Fernando, resulta continuo en todo el programa. Puede contemplarse también en los muros de esta iglesia un Apostolado en figurados medallones sobre los pilares, cerrado con las presencias de Cristo y la Virgen en el coro, actualmente ocultos tras el nuevo órgano, y las representaciones en grisalla, a los lados del cancel de entrada de la Antigua Ley y el Celo religioso. Pero lo que tradicionalmente ha despertado mayor interés por su originalidad en la pintura sevilana son los seis tapices simulados con escenas históricas y textos alusivos al hecho ubicados en las partes altas de los muros de la nave. Estos episodios, imágenes de la sumisión del poder temporal al religioso mediante el respeto al orden sacro, muestran a: San Martín presidiendo la mesa del emperador (Foto 3), Carlos II cede su carroza a un sacerdote portador del viático, San Ambrosio niega la entrada en el templo al emperador Teodosio, El emperador Constatino en el Concilio de Nicea, San León detiene a Atila a las puertas de Roma y Federico Barbarroja pide perdón al Papa Alejandro III. Todas estas pinturas desde la cúpula hasta los píes del templo, fueron diseñadas por Valdés Leal y finalmente ejecutadas por su hijo Lucas Valdés. En la sacristía, pequeño espacio lateral en el muro izquierdo del antepresbiterio cubierto a 
baja altura con techo plano, se pintó con diestro sentido de la perspectiva el Triunfo de la Santa Cruz. Esta última obra fue realizada por los Valdés Leal desde principios de 1687 y es de las más bellas del conjunto. No podemos olvidar finalmente los murales exteriores del pórtico de la iglesia, en muy mal estado de conservación, donde se representa la Llegada de sacerdotes peregrinos al Hospital y el Auxilio a los sacerdotes en la enfermería del Hospital. Ambas obras son de Lucas Valdes, así como los modelos de las mismas también conservados en el hospital ${ }^{23}$.

En esencia el único continuador y colaborador final de la labor artística de Juan Valdés Leal fue su hijo Lucas Valdés ( 166 | - | 725), un correcto pintor de buenas cualidades como muralista aunque falto del talento de su progenitor. Su labor fue destacada en la
Sevilla de finales siglo XVII, culminando los proyectos paternos, como hemos señalado, y realizando otros menores; pues sus mejores obras personales en este campo son ya cronológicamente del siglo XVIII. Debe también señalarse que Lucas Valdés fue maestro de pintores muralistas de la generación posterior entre los que sobresale Domingo Martínez.

Desgraciadamente las obras murales seicentistas de Lucas no se conservan, aunque sí hay abundantes referencias sobre ellas. Destaquemos aquí la desaparecida decoración del claustro y escalera principal del convento de los Trinitarios Descalzos de Sevilla que fue ejecutada hacia 1690. Ya citamos anteriormente las pinturas del claustro y quizás portería del convento Casa Grande de San Francisco de Sevilla, contratadas en $1700^{24}$.

\section{Notas}

I. "La pintura mural sevillana desde el siglo XVI al XVIII", en Formación Profesional y Artes Decorativas en Andalucía y América, Consejería de Cultura y Medio Ambiente, Junta de Andalucía, Sevilla, 1991.

2. BLUNT, A., La Teoría de las artes en Italia (1450-1600), Oxford, 1.956, ed. Española, Madrid, 1.976, págs. I 16-117.

3. Discorso intorno le immagini sacre e profane, Bolonia, 1582.

4. MARAVALL, J. A., La cultura del Barroco, $3^{\mathrm{a}}$ ed., Barcelona 1.983, pág. 48.

5. No hay peor sordo..., en Obras dramáticas completas, t. III, Madrid, 1962, acto III, escena VII, p. 1056.

6. Esta coincidencia de algunos aspectos hispanos en el Barroco fue puesta de manifiesto por: WEISBACH, W., El Barroco, arte de la Contrarreforma, ed. Española, Madrid, I.942; y MALE, E.,L'art religieux aprés le Concilie de Trente, París, 1.932. También han puesto de manifiesto esta influencia WATKIN, S., Catholic art and culture, Londres, 1.942; TAPIE, V. L., Le Barroque, París, I.96I.

7. WEISBACH, W.,ob. cit., págs. 56 y 57.

8. Finalizado al parecer hacia 1638 , fue publicado de forma póstuma pues Pacheco falleció en 1644. Ed. 1991,pp. 453-466.

9. Arte de la pintura..., ed. 1991, p. 464.

10. Id., p. 465.

Il. Id. p. 461.

12. Ceán Bermúdez,J.A., Diccionario histórico de los más ilustres profesores de las Bellas Artes de España, I800, t. III, p. I I6. Pérez Sánchez, A., Pintura española de bodegones y floreros de 1600 a Goya, Madrid, 1983-1984, p. 46I.

13. Id., p. 5I I; Valdivieso, E. y Serrera, J.M., Ob. cit.., Madrid, 1985, p. 187.

14. Valdivieso, E. y Serrera, J.M., Ob. cit., Madrid, 1985, pp. 176177. Valdivieso, E., Historia de la pintura sevillana, Sevilla, 1986, pp. $128-130$.

15. Morales, A. Sanz, Ma.J., Serrera, J.M. y Valdivieso,E., Guía artística de Sevilla y su provincia, Sevilla, I98I, pp. 544-545.
16. Martínez Ripoll, A., Francisco de Herrera "el Viejo", Sevilla, 1978. Valdivieso, E., Historia de la Pintura Sevillana, Sevilla, 1986, pp. 158-167.

17. Martínez Ripoll, A., La iglesia del Colegio de San Buenaventura, Sevilla, 1976; Francisco de Herrera "El Viejo", Sevilla, 1978. pp. 85-92. Sebastián, S.,Contrarreforma y Barroco, Madrid, 1985, p. 285 y ss. Fernández López, J., Programas iconográficos de la pintura barroca sevillana del siglo XVII, Sevilla, 1991, pp. 69. 74.Chavero Blanco, F., "La iglesia del colegio de San Buenaventura de Sevilla. Lectura iconológica", en El franciscanimo en Andalucía (III Curso de Verano), Códoba, 1999, págs. 55-84.

18. .- Delenda, O., "Zurbarán interprète idèal de la ContraRéforme espagnole" en La revue du Louvre et des Musées de France, 1988, p. 120.

19. Sobre este pintor resultan imprescindibles los trabajos de: Pérez Sánchez, A.J., Carreño, Rizi, Herrera y la pintura madrileña de su tiempo (1650-1700), Catálogo de la Exposición, Madrid, 1983, p. 92-101 y 266-275. Valdivieso, E., ob. cit.,1986, pp. 199-204.

20. Sobre este pintor debe consultarse: Kinkead, D.Th., Valdés Leal, New York, 1978. Valdivieso, E., Valdés Leal, Sevilla, 1988.

21. Valdivieso, E. y Serrera, J.M., El Hospital de la Caridad de Sevilla, Sevilla, 1980. Valdivieso, E., Guia de Santa Caridad, Sevilla, 1988.

22. Valdivieso, E. y Morales, A., Sevilla oculta, 1980, p.21; Valdivieso, E., ob. cit., 1986, 288-289; Id., ob. cit., 1988, pp. 199-200 y 286-287. Pareja López, E., "Obras maestras del arte", en Real Monasterio de San Clemente, Córdoba, 1999. 36।-368.

23. Valdivieso, E., ob. cit., 1988, pp. 200-205. Valdivieso, E. y Fernández López, J., "El patrimonio artístico", en Los Venerables, Sevilla, 1991, pp. 73-III.

24. Fernández López, J., Lucas Valdés ( 66 | - | 725), en prensa. 